\title{
OPTIMASI PENGENDALI PID PADA PESAWAT AUTOPILOT BERBASISKAN ALGORITMA GENETIKA
}

\author{
Muhammad Ilhamdi Rusydi \\ Jurusan Teknik Elektro, Fakultas Teknik, Universitas Andalas \\ Corresponding author, e-mail: rilhamdi@ft.unand.ac.id
}

\begin{abstract}
Abstrak-Teknologi pada saat sekarang ini telah menyentuh sisi otomatisasi yang handal. Kemampuan mesin untuk bekerja secara mandiri menjadi suatu hal yang sangat penting dewasa ini, begitu juga pada industri pesawat. Pesawat yang dapat menentukan lintasan terbangnya sendiri disebutkan juga dengan autopilot. Pada penelitian ini telah dikembangkan sistem pengendalian pesawat yang dapat menjaga ketinggian terbangnya sesuai dengan yang diinginkan pilot. Dengan menggunakan fungsi alih dari sistem pesawat, maka pengendali PID dirancang berdasarkan metoda algoritma genetika atau PID-GA. Performa kendali PID-GA ini ternyata jauh lebih baik jika dibandingkan dengan metoda pengendali PID-Ziegler Nichlos (PID-ZN). Metoda pengendali PID-GA yang dipilih bekerja pada nilai batas=10, banyak generasi=30 dan populasi sebesar 50. Konstanta proporsional, integral dan derivatif yang dihasilkan adalah 9,66; 9,15 dan 9,06. Dengan kriteria tersebut, waktu naik sistem diperbaiki dari 0,732 detik pada PID-ZN menjadi 0,55 detik pada PID-GA. Sistem juga lebih cepat stabil, dimana pada PID-ZN sistem stabil setelah 19,1 detik sedangkan pada PID-GA sistem sudah stabil dalam jangka waktu 5,3 detik. Hasil ini memperlihatkan betapa kendali PID-GA bekerja sangat baik pada sistem pesawat autopilot.
\end{abstract}

Kata Kunci : Autopilot, Algoritma Genetika, PID.

\begin{abstract}
Nowadays, technology counts automation as one of the considerable features on it. The ability of machine to work independently become very important, like in aircraft industry. Aircrafts which able to decide their own path are called autopilot. In this research, the control system of pesawat was designed to keep it fly on the reference of high based on the pilot demands. Using the transfer function of aircraft, PID controller was designed based on genetic algorithm (PID-GA). The performance of PID-GA was compared to the PID which was tuned by Ziegler-Nichlos. The result showed that the chosen PID-GA which the threshold, generation and population are 10, 30, 50 performed better performance than PID-ZN. The parameter of proportional, integral and derivate controller are 9,66, 9,15 and 9.06. The specification of the system performance based on PID-GA were 0.55 second of rise time, 5.3 second of rise time. This result were better than the PID-ZN results. The system performance based on PID-ZN 0.732 second of rise time and 19.1 second of settling time..
\end{abstract}

Keywords : Autopilot, Genetic Algorithm, PID

Copyright $(2016$ JNTE. All rights reserved

\section{PENDAhuluan}

Perkembangan teknologi saat ini telah merambah ke segala sisi kehidupan manusia, baik itu dalam skala besar seperti industri maupun skala kecil seperti kebutuhan sehari-hari manusia. Teknologi juga hadir dalam dunia kesehatan, militer, pendidikan, pertanian, komunikasi, transportasi, dll.

Salah satu alat transportasi adalah pesawat yang merupakan transportasi udara. Performa dari sebuah pesawat sangat berhubungan dengan jarak tempuh, daya tahan, kemampuan mendaki, jarak yang ditempuh untuk untuk mendarat dan lepas landas, serta optimisasi dari lintasan terbang[1].
Pesawat dikembangkan sekarang ini agar dapat bergerak dengan pilot otomatis atau disebut juga dengan autopilot. Kemampuan kerja seperti ini mempermudah pekerjaan dari seorang pilot yang dulunya sangat susah dan melelahkan menjadi lebih sederhana.

Penelitian tentang autopilot ini berkembang pesat untuk terus dapat memperbaiki performa dari pesawat itu sendiri. Pada penelitian[2], pengendalian pergerakan lateral dari pesawat pada saat pendaratan dikendalikan dengan menggunakan jaringan syaraf tiruan dan sistem navigasi radio. Penelitian ini mendapatkan karakteristik respon sistem yang bagus dan nilai puncak yang kecil. 
Penelitian lainnya mengenai pendaratan dari pesawat adalah[3]. Pada penelitian tersebut, fokus pengendalian diberikan pada pergerakan longitudinal selama proses pendaratan dengan menggabungkan $\mathrm{H}_{2} / \mathrm{H}_{\infty}$ dan teknik pengendali invers dinamik.

Pekerjaan lainnya[4] telah berhasil memodelkan tiltrotor dari pesawat yang dapat berfungsi baik sebagai heli kopter maupun sebagai pesawat fixed-wing.

Menggunakan rekonstruksi kesalahan dari sensor Inertial Measurement Unit (IMU), perhitungan pergerakan pesawat berdasarkan sumbu putar bumi telah dilakukan dengan menggunakan data penerbangan yang sebenarnya[5].

Perancangan kendali autopilot pada pegerakan longitudinal dilakukan oleh [6]. Pada penelitian ini ditampilkan perbandingan antara respon sistem dengan menggunakan PID tradisional dan self-adaptive fuzzy PID. Hasilnya memperlihatkan bahwa self-adaptive fuzzy PID lebih unggul dari pada PID saja. Pengendali menggunakan fuzzy cukup banyak digunakan saat ini, seperti pada [7] yang mengendalikan sistem mobil robot.

Penelitian ini dikerjakan untuk merancang dan mengetahui performa sistem kendali PID yang parameternya dioptimasi oleh sistem algoritma genetika (PID-AG). Performa sistem tersebut dibandingkan dengan PID ZieglerNichlos (PID-ZN) dan sistem tanpa menggunakan pengendali.

\section{PESAWAT AUTOPILOT}

Suatu psesawat sederhana mempunyai tiga kontrol dasar, yaitu: aileron, elevator dan rudder. Suatu aileron dapat mengontrol pergerakan lateral (roll). Elevator dapat mengontrol pergerakan longitudinal (pitch). Rudder dapat mengontrol pergerakan directional (yaw). Gambar 1 mengilustrasikan tiga tipe pegerakan pada pesawat tersebut.

Tipe autopilot yang paling dasar adalah tipe dimana robot bergerak lurus pada ketinggian yang tetap dengan sedikit bahkan hampir tidak ada manuver yang dilakukan. Pada pergerakan autopilot ini, referensi diberikan untuk mengaktifkan sistem autopilot. Jika posisi pitch berbeda dari referensi maka tegangan $e_{g}$ akan dihasilkan oleh generator sinyal pada gyro vertikal. Servo elevator dapat berupa elektromekanik atau hidrolik dengan katup (valve) yang dioperasikan secara elektrik. Servo menentukan posisi elevator, yang menyebabkan pitch pesawat berubah berdasarkan sumbu-Y dan mengembalikannya kepada posisi pitch yang diinginkan.

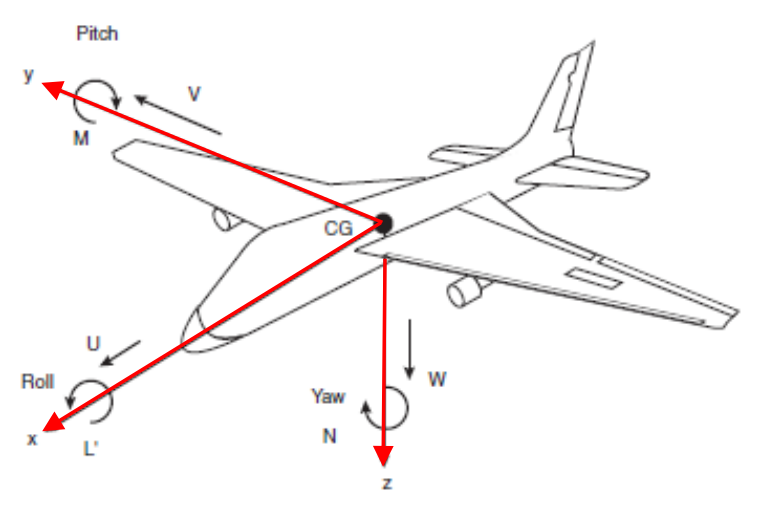

Gambar 1. Tiga tipe pegerakan pada pesawat.

Skema dari Autopilot pesawat untuk pergerakan longitudinal ditunjukkan pada Gambar 2 berdasarkan[1].

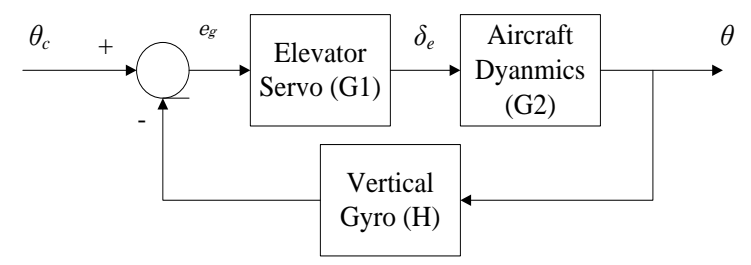

Gambar 2. Skema pesawat autopilot untuk pegerakan longitudinal

Sistem dirancang dengan menggunakan sistem pesawat autopilot sebagai model sistem. Model ini terdiri dari sistem servo dan dinamik pesawat, dengan sedikit penyederhanaan dari[1] maka fungsi transfer yang digunakan untuk servo dan dinamik pesawat adalah (1) dan (2) :

$$
\begin{aligned}
& \mathrm{G} 1=\frac{1}{\mathrm{~s}+1} \\
& \mathrm{G} 2=\frac{1}{\mathrm{~s}^{2}+2,8 \mathrm{~s}+3,24}
\end{aligned}
$$

Dengan umpan balik $\mathrm{H}=1$, maka fungsi transfer dari sistem pesawat autopilot tersebut adalah (3)

$$
\mathrm{FT}_{\text {sistem }}=\frac{1}{\mathrm{~s}^{3}+3,8 \mathrm{~s}^{2}+6,04 \mathrm{~s}+3,24}
$$




\section{PENGENDALI PID}

Struktur sistem kontrol dengan pengendali PID diilustrasikan oleh Gambar 3. Hasil pengurangan antara sinyal referensi, $r(t)$, dengan sinyal keluaran $\mathrm{y}(\mathrm{t})$ adalah galat yang disimbolkan dengan $\mathrm{e}(\mathrm{t})$. Hasil pengurangan tersebut menjadi input bagi masing-masing pengendali proposional, integral dan derifatif. Penjumlahan dari semua aksi pengendali terhadap galat dilambangkan dengan $u(t)$. Hubungan antara $\mathrm{u}(\mathrm{t})$ dan galat diperlihatkan oleh (4) atau dinyatakan dalam (5) dengan $K_{p}, K_{i}$ dan $K_{D}$ adalah konstanta untuk pengendali proposional, integral dan derivatif [8].

$$
\begin{aligned}
& u(t)=K_{P}\left[e(t)+\frac{1}{T_{I}} \int_{0}^{t} e(t) d t+T_{D} \frac{d e(t)}{d t}\right] \\
& u(t)=K_{P} e(t)+K_{I} \int_{0}^{t} e(t) d t+K_{D} \frac{d e(t)}{d t}
\end{aligned}
$$

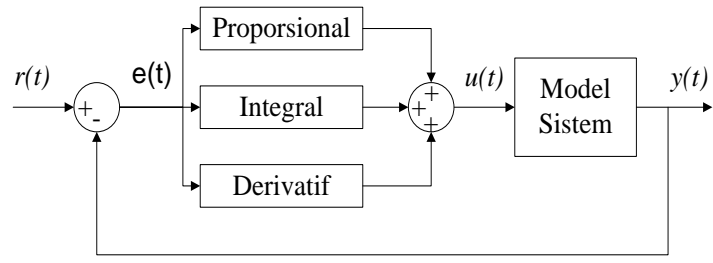

Gambar 3. Struktur pengendali PID pada sistem.

Konstanta PID didapatkan menggunakan dua metoda, yaitu metoda Ziegler-Nichlos dan metoda algoritma genetika. Sebagai pembanding kinerja pengendali tersebut, maka dilakukan juga analisa dari sistem tanpa pengendali. Karakteristik yang diteliti pada sistem adalah waktu naik, waktu puncak, maksimum lewatan dan galat keadaan tunak.

\section{PENGENDALI PID-ZN}

Konstanta PID dengan metoda ZieglerNichlos didapatkan melalui beberapa tahapan. Langkah pertama adalah dengan menentukan besarnya $T_{I}$ menjadi $\infty$ dan $T_{D}$ menjadi 0 sehingga diperoleh fungsi transfer dari pengendali adalah $K_{p}$ dengan digram blok seperti yang diperlihatkan oleh Gambar 4. Berdasarkan diagram blok tersebut, maka didapatkanlah fungsi transfer (6).

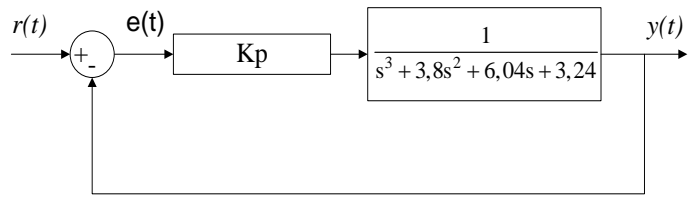

Gambar 4. Diagram blok sistem jika $T_{I}=\infty$ dan $\mathrm{T}_{\mathrm{D}}=0$.

$$
\frac{Y(s)}{R(s)}=\frac{1}{s^{3}+3,8 s^{2}+6,04 s+3,24+K_{P}}
$$

Nilai dari $K_{P}$ dapat dihitung menggunakan kriteria kestabilan Routh sbb:

$$
\begin{array}{l|cc}
\cline { 2 - 3 } \mathrm{s}^{3} & 1 & 6,04 \\
\mathrm{~s}^{2} & 3,8 & 3.24+\mathrm{K}_{\mathrm{p}} \\
\mathrm{s}^{1} & \left(19,712-\mathrm{K}_{\mathrm{P}}\right) / 3.8 \\
\mathrm{~s}^{0} & 3.24+\mathrm{K}_{\mathrm{P}} &
\end{array}
$$

Dengan melakukan pengamatan pada kolom pertama, maka titik kritis dari sistem ini adalah $K_{P}=19,72$. Nilai tersebut disebutkan juga dengan titik kritis penguatan atau dilambangkan dengan $\mathrm{K}_{\mathrm{CR}}$. Dengan nilai $\mathrm{K}_{\mathrm{P}}$ tersebut, maka didapatkan frekuensi $\left(\omega_{\mathrm{P}}\right)$ yang berdasarkan persamaan karakteristik (7) adalah sebesar 2,46 Hz dan perida $\left(T_{P}\right)$ sebesar 2,56 detik.

$$
(\mathrm{j} \omega)^{3}+3,8(\mathrm{j} \omega)^{2}+6,04(\mathrm{j} \omega)+22,96=0
$$

Sesuai dengan aturan Ziegler-Nichlos dalam menetapkan nilai $K_{P}, T_{I}$ dan $T_{D}[6]$ berdasarkan nilai kritis penguatan, maka nilai $K_{P}, T_{I}$ dan $T_{D}$ ditunjukkan oleh (8), (9) dan (10).

$$
\begin{aligned}
\mathrm{K}_{\mathrm{P}} & =0,6 \times \mathrm{K}_{\mathrm{CR}} \\
& =0,6 \times 19,72 \\
& =11,83 \\
\mathrm{~T}_{\mathrm{I}} & =0,5 \times \mathrm{T}_{\mathrm{P}} \\
& =0,6 \times 2,56 \\
& =1,54
\end{aligned}
$$




$$
\begin{aligned}
\mathrm{T}_{\mathrm{D}} & =0,125 \times \mathrm{T}_{\mathrm{P}} \\
& =0,125 \times 2,56 \\
& =0,32
\end{aligned}
$$

Menggunakan nilai $K_{P}, T_{I}$ dan $T_{D}$ tersebut maka diperoleh persamaan fungsi transfer pengendali menjadi (12) dan fungsi transfer lingkar tertutup sistem dengan menggunakan pengendali PID metoda Ziegler-Nichols adalah (13).

$$
\begin{aligned}
& \frac{U(s)}{E(s)}=\frac{3,78 s^{2}+11,83 s+1,68}{s} \\
& \frac{Y(s)}{R(s)}=\frac{3.78 s^{2}+11.83 s+1.68}{s^{4}+3.8 s^{3}+9.82 s^{2}+15.07 s+1.68}
\end{aligned}
$$

\section{PENGENDALI PID-AG}

Perbaikan kinerja sistem dilakukan dengan perancangan sistem PID berdasarkan metoda algoritma genetika. Proses algoritma genetika yang digunakan diperlihatkan oleh Gambar 5. Populasi awal yang digunakan pada sistem ini adalah 50, nilai populasi ini diambil secara acak.

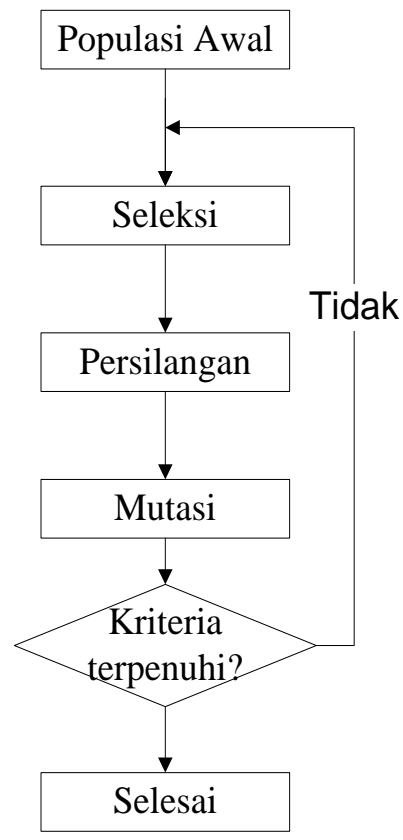

Gambar 5. Diagram alir algoritma genetika.

Seleksi individu untuk menghasilkan generasi yang berhasil, memainkan aturan yang terpenting pada sistem algoritma genetik. Pada penelitian ini, tipe seleksi yang digunakan adalah metoda pemeringkatan nilai normalisasi dari distribusi geometri, sesuai dengan (13). Nilai $r$ adalah normalisasi dari distribusi, $\mathrm{q}$ adalah probabilias dari terpilihnya populasi terbaik dan $\mathrm{n}$ adalah jumlah anggota dalam populasi. Menggunakan nilai fitness dari setiap individu, maka individu yang lebih baik mempunyai peluang terpilih yang lebih tinggi[6].

$$
r=\frac{q}{1-(1-q)^{n}}
$$

Persilangan yang digunakan dalam penelitian ini adalah metoda interpolasi dari dua orang tua untuk menghasilkan 2 anak, seperti pada (14) dan (15). Nilai anak pertama dan kedua adalah $\mathrm{c}_{1}$ dan $\mathrm{c}_{2}$. Nilai orang tua pertama dan kedua adalah $\mathrm{p}_{1}$ dan $\mathrm{p}_{2}$, sedangkan a adalah bilangan acak yang bebas dipakai.

$$
\begin{aligned}
& \mathrm{c}_{1}=\mathrm{p}_{1} * \mathrm{a}+\mathrm{p}_{2} *(1-\mathrm{a}) \\
& \mathrm{c}_{2}=\mathrm{p}_{1} *(1-\mathrm{a})+\mathrm{p}_{2} * \mathrm{a}
\end{aligned}
$$

Pada tahap mutasi terdapat perubahan parameter yang diambil secara acak dari orang tua menggunakan distribusi probabilitas.

\section{HASIL DAN PEMBAHASAN}

Penelitian ini telah melakukan pengujian dalam berbagai macam aspek kemungkinan yang ada. Pengujian pertama yang dilakukan adalah pengujian performa sistem tanpa menggunakan pengendali. Pengujian selanjutnya adalah pengujian performa sistem menggunakan PID-ZN. Dan yang terakhir adalah pengujian sistem menggunakan PID-GA.

Tabel 1. Karakteristik sistem tanpa kendali dan dengan PID-ZN terhadap masukan step.

\begin{tabular}{lcc}
\hline \multicolumn{1}{c}{ Parameter } & $\begin{array}{c}\text { Tanpa } \\
\text { Kendali }\end{array}$ & PID-ZN \\
\hline Waktu naik & 3,81 & 0,732 \\
Waktu puncak & 8,71 & 1,43 \\
Settling time & 12,5 & 19,1 \\
Maksimum & 8,26 & 8,72 \\
lewatan & 0 & 0 \\
Galat & & \\
\hline
\end{tabular}


Pengujian sistem menggunakan masukan step baik itu yang tanpa menggunakan kendali dan juga sistem yang menggunakan kendali PIDZN diperlihatkan oleh Gambar 6 dan Gambar 7. Dengan membaca Tabel 1, ada beberapa hal yang menarik pada dua buah sistem ini, pertama adalah sistem PID-ZN dapat meningkatkan performa sistem secara signifikan dengan menekan waktu puncak yang sebelumnya 8,71 detik menjadi hanya 1,43 detik saja. Begitu juga halnya dengan waktu naik sistem dengan menggunakan PID-ZN tidak sampai lebih dari $1 / 5$ saja dari waktu yang yang dibutuhkan sistem tanpa kendali untuk bernilai $90 \%$ dari masukan pertama kali.

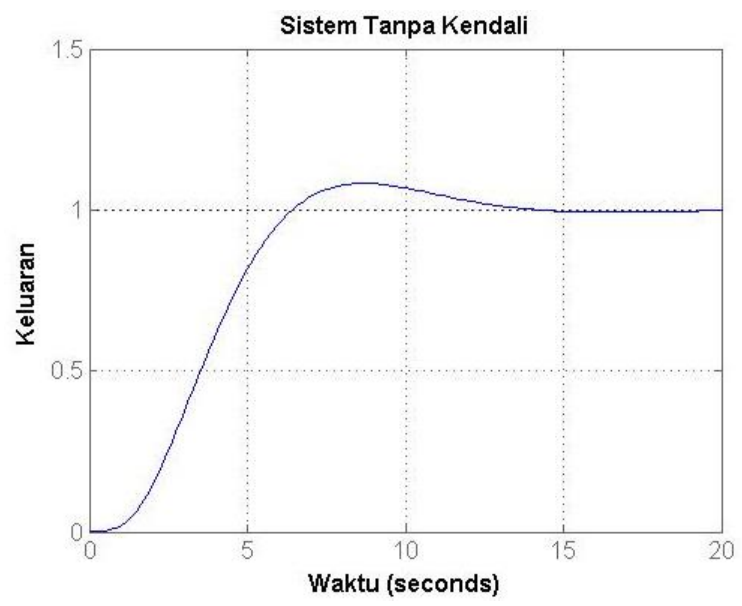

Gambar 6. Respon sistem tanpa kendali.

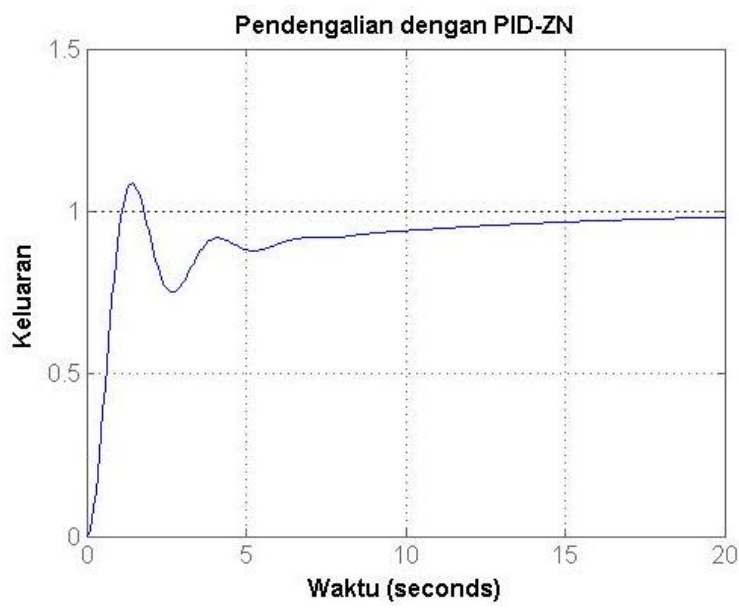

Gambar 7. Respon sistem dengan pengendali PID-ZN.

Kedua sistem, baik itu yang tanpa kendali maupun dengan kendali tidak memiliki galat pada kondisi tunak. Berdasarkan hasil penelitian ini, ternyata ditemukan bahwa sistem menggunakan PID-ZN membutuhkan waktu yang lebih lama untuk mencapai nilai pada rentang 2\% dari pada masukan. Sistem tanpa kendali memiliki settling time sekitar 12 detik, sedangkan sistem menggunakan PID-ZN membutuhkan waktu sampai dengan 19,1 detik. Hal ini memperlihatkan bahwa sistem dengan kendali PID-ZN membutuhkan waktu yang lebih lama untuk mencapai kestabilan.

Sistem kendali PID dikembangkan juga dengan menggunakan algoritma genetika. Terdapat 3 masukan pada sistem PID-GA ini, yaitu jumlah populasi, nilai batas, dan banyaknya generasi. Pada percobaan pertama, ditetapkan nilai populasi dan banyaknya generasi bernilai tetap, sedangkan nilai batas dibuat bervariasi. Nilai populasi dan banyak generasi yang dicoba adalah 20 dan 20, sedangkan nilai batas bernilai 20, 15, 10, 5 dan 1. Berdasarkan nilai yang ada di Tabel 2, didapatkan bahwa waktu naik sistem semakin besar jika nilai batas dikecilkan. Hal ini berarti sistem lama mencapai kondisi stabilnya. Walaupun begitu, maksimum lewatan sistem tidak lebih dari $0,12 \%$ ketika nilai batas bernilai 1. Berdasarkan percobaan ini maka didapatkanlah nilai batas yang akan di ambil adalah 10 .

Tabel 2. Respon sistem terhadap nilai populasi $=20$, banyak generasi $=20$, dan nilai batas yang bervariasi.

\begin{tabular}{|c|c|c|c|c|c|}
\hline \multirow[t]{2}{*}{ Parameter } & \multicolumn{5}{|c|}{ Batas } \\
\hline & 20 & 15 & 10 & 5 & 1 \\
\hline Waktu naik & 0,33 & 0,40 & 0,56 & 1,74 & 6,71 \\
\hline $\begin{array}{l}\text { Waktu } \\
\text { puncak }\end{array}$ & 0,71 & 0,87 & 1,08 & 4,35 & 16,1 \\
\hline Settling time & 4,89 & 4,67 & 5,11 & 6,62 & 10,3 \\
\hline $\begin{array}{l}\text { Maksimum } \\
\text { lewatan }\end{array}$ & 18,5 & 15,2 & 5,79 & 7,65 & 0,12 \\
\hline Galat & 0 & 0 & 0 & 0 & 0 \\
\hline
\end{tabular}

Berdasarkan hasil percobaan pada Tabel 2, maka percobaan selanjutnya adalah dengan memvariasikan banyak generasi terhadap nilai populasi $=20$ dan nilai batas $=10$. Terlihat pada Tabel 3 bahwa variasi generasi tidak berpengaruh signifikan terhadap sistem dengan nilai populasi dan batas yang telah ditetapkan. Berdasarkan percobaan ini maka diambilnya nilai batas sebesar 10 dan banyak generasi 
sebesar 30. Alasan pemilihan ini adalah karena lebih mengutamakan kecepatan sistem mencapai kestabilan dan menganggap perbedaan $\pm 0,5 \%$ pada maksimum lewatan bernilai sama.

Percobaan selanjut adalah dengan mempertahankan nilai batas dan banyak generasi, sedangkan nilai populasi bervariasi dari rentang $50 \mathrm{~s} / \mathrm{d} 55$. Hasil percobaan ini dapat terlibat pada Tabel 4. Dari sekian banyak kombinasi yang telah dirancang, ternyata didapatkan nilai populasi sebesar 50 menghasilkan waktu naik yang lebih cepat dengan maksimum lewatan yang rendah. Dengan nilai batas, banyak generasi dan populasi sebsar 10, 30 dan 50, maka didapatkan konstanta proporsional, integra dan derifatif sebesar 9,66; 9,15 dan 9,06. Perbandingan enam parameter kendali sistem PID-ZN dan sistem PID-GA diperlihatkan oleh Tabel 4.

Tabel 3. Respon sistem terhadap nilai populasi $=20$, nilai batas 10 , dan banyak generasi yang bervariasi.

\begin{tabular}{|c|c|c|c|c|c|}
\hline \multirow[t]{2}{*}{ Parameter } & \multicolumn{5}{|c|}{ Banyak Generasi } \\
\hline & 20 & 30 & 40 & 50 & 60 \\
\hline Waktu naik & 0,56 & 0,54 & 0,54 & 0,54 & 0,54 \\
\hline $\begin{array}{l}\text { Waktu } \\
\text { puncak }\end{array}$ & 1,08 & 1,03 & 1,04 & 1,05 & 1,03 \\
\hline Settling time & 5,1 & 5,2 & 5,3 & 5,1 & 5,2 \\
\hline $\begin{array}{l}\text { Maksimum } \\
\text { lewatan }\end{array}$ & 5,8 & 5,6 & 5,1 & 6,1 & 5,7 \\
\hline Galat & 0 & 0 & 0 & 0 & 0 \\
\hline
\end{tabular}

Perbandingan kinerja sistem kendali pesawat autopilot dengan menggunakan kendali PID-ZN dan PID-GA diperlihatkan oleh Tabel 5. Sistem
PID-GA berhasil memperbaiki sistem lebih cepat mencapai titik kestabilannya. Selain itu, berdasarkan nilai maksimum lewatan, sistem PID-GA juga telah menekan parameter tersebut yang sebelumnya mencapai $8,72 \%$ menjadi $4,6 \%$.

Tabel 5. Karakteristik sistem PID-ZN dan PIDGA yang dipilih terhadap masukan step.

\begin{tabular}{lcc}
\hline \multicolumn{1}{c}{ Parameter } & PID-ZN & PID-GA \\
\hline Waktu naik & 0,732 & 0,55 \\
Waktu puncak & 1,43 & 1,05 \\
Settling time & 19,1 & 5,3 \\
Maksimum & 8,72 & 4,6 \\
lewatan & 0 & 0 \\
Galat & \\
\hline
\end{tabular}

\section{KESIMPULAN}

Pada penelitian ini telah dilakukan perancangan pengendali PID terhadap sistem autopilot. Parameter konstanta pengendali PID didapatkan dengan metoda algoritma genetika. Performa sistem dengan pengendali PID-GA ini ternyata menghasilkan kinerja sistem yang jauh lebih baik dibandingkan dengan metoda pengendali PID-ZN. Kendali PID-GA meningkatkan performa sistem tanpa kendali secara siknifikan. Performa sistem dibandingkan melalui parameter masa peralihan dan kondisi tunak, yaitu waktu naik, waktu puncak, settling time, maksimum lewatan dan galat. Oleh karena itu, metoda PID-GA dapat dimanfaatkan dalam merancangan sistem kendali autopilot pada gerakan longitudinal.

Tabel 4. Respon sistem terhadap nilai batas 10 , banyak generasi=30, dan populasi yang bervariasi.

\begin{tabular}{lcccccccccc}
\hline Parameter & \multicolumn{10}{c}{ Populasi } \\
\cline { 2 - 11 } & 20 & 30 & 40 & 50 & 60 & 51 & 52 & 53 & 54 & 55 \\
Waktu naik & 0,54 & 0,54 & 0,54 & 0,55 & 0,56 & 0,54 & 0,54 & 0,55 & 0,54 & 0,55 \\
$\begin{array}{l}\text { Waktu } \\
\text { puncak }\end{array}$ & 1,03 & 1,04 & 1,03 & 1,05 & 3,17 & 1,03 & 1,04 & 1,08 & 1,04 & 1,04 \\
$\begin{array}{l}\text { Settling } \\
\text { time }\end{array}$ & 5,2 & 5,3 & 5,1 & 5,3 & 5,23 & 5,3 & 5,4 & 5,3 & 5,2 & 5,4 \\
$\begin{array}{l}\text { Maksimum } \\
\text { lewatan }\end{array}$ & 5,6 & 5,5 & 5,8 & 4,6 & 6,52 & 5,2 & 4,9 & 5,7 & 5,6 & 4,5 \\
Galat & 0 & 0 & 0 & 0 & 0 & 0 & 0 & 0 & 0 & 0 \\
\hline
\end{tabular}




\section{DAFTAR PUSTAKA}

[1] John, H.B., Automatic Control of Aircraft and Missiles, ed. 2, Willey (1991).

[2] Mihai, L., Romulus, L., Automatic Control of Aircraft Lateral-directional Motion During Landing Using Neural Networks and Radio-Technical Subsystems, Neurocomputing 171, 471481 (2016).

[3] Romulus, L., Mihai, L., Application of $\mathrm{H}_{2} / \mathrm{H}_{\infty}$ and dynamic inversion techniques to aircraft landing control, Aerospace Science and Technology 46, 146-158 (2015).

[4] Xinhua, W., Lilong, C., Mathematical Modelling and Control of a Tilit-Rotor Aircraft, Aerospace Science and Technology 47, 473-492 (2015).

[5] Peng L., Erik-Jan van Kampen, Cornelis de Visser, Qiping, C., Nonlinear Aircraft Sensor Fault Reconstruction in the Presence of Disturbances Validated by Real Flight Data, Control Engineering Practice 49, 112-128 (2016).

[6] Andrew C., Peter F., Hartmut P., Carlos F., Genetic Algorithm Toolbox, Version 1.2, Department of Automatic Control and System Engineering, University of Sheffield.

[7] Darwison, Ilhamdi Rusydi, Rico Fajri., Kontrol Posisi Robot Mobil Menggunakan Logika Fuzzy dengan Sensor Ultrasonik, JNTE 1, 33-41(2012).

[8] Katsuhiko Ogata., Modern Control Engineering, ed. 3, Tom Robbins (1997).

\section{Biodata Penulis}

Muhammad Ilhamdi Rusydi adalah seorang pengajar di Jurusan Teknik Elektro Unand sejak tahun 2005 dengan bidang keahlian Human and Intelligent Control Machine. 